\title{
INDIVIDUALIZATION AND THE IDEAL OF SELF-REALIZATION IN CONDITIONS OF REFLEXIVE MODERNITY
}

\begin{abstract}
Individualization as a modernization social phenomenon is of a highly ambivalent character. On the one hand, it represents the emancipation of individuals from general pressures of the society, from the traditional relations of domination and material dependence, the reduction of social pressure on the reproduction of traditional, typified social roles and lifestyles associated with social status and gender. On the other hand, individualization leads, under the current conditions, to increasing isolation of individuals in the context of instrumentalized, anonymous and fragmentary social relations and contacts, ultimately to forms of social deprivation. Emancipation creates room for an individual and subjectively gripped biography, for individual subjectively answering the question of good life, which promotes the ideal of individual self-realization as a new ideal of behavior and good life. However, the parallel process of social isolation seriously restricts and distorts the possibilities of its application. Based on this contradiction, this paper focuses on the critical exploration of the ways and forms of applying the ideal of self-fulfillment in contemporary society.
\end{abstract}

Keywords: individualization, self-realization, society, modernity, Axel Honneth

\section{Introduction}

The social process of individualization of modern societies and the associated moral individualism are, in the context of moral and social philosophy, the subject of controversial and even contradictory interpretations. In particular, liberal and postmodern approaches appreciate individualization as a process of increasing the autonomy of the individual, weakening of power and ideological pressures and pluralization of the society [1]. Individualization is perceived as an emancipatory process that overcomes all forms of dominion that in some way restrain a man. Conservative, communitarian, and approaches based on the critical theory of society are in principle more cautious and skeptical in the interpretation and evaluation of individualization. They try to point out that the development of modern societies overcomes the traditional forms of dominion, but at the same time it can lead to the emergence of new forms. Contradiction of these interpretations can also be illustrated on the theories of Charles Taylor and Christopher Lasch. While Taylor, in connection with individualization and self-realization, talks about the culture and ethics of authenticity as about "something relatively new and peculiar to modern culture" [2, p. 25], Lasch on the contrary, sees the culture of narcissism, "the culture of competitive individualism, which in its decadence has carried the logic of individualism to the extreme of a war of all against all, the pursuit of happiness to the dead end of a narcissistic preoccupation with the self" $[3, p . x v]$. One of the key issues that arises in these interpretations is the question of how the profound structural changes within modern society are reflected in its moral life forms and individual biographies. The aim of this paper is to examine the critical thesis formulated in this context by Axel Honneth according to which "the claims to individual self-realization which have rapidly multiplied, beginning with the historically unique concatenation of entirely disparate processes of individualization in the Western societies of thirty or forty years ago, have so definitely become a feature of the institutionalized expectations inherent in social reproduction that the particular goals of such claims are lost and they are transmuted into a support of the system's legitimacy $/ . . . /$ the processes which once promised an increase of qualitative freedom are henceforth altered into an ideology of de-institutionalization" [4, p. 467]. The intention is to build on Honneth argumentation and to develop it, partly to concretize it and extend it to other context.

\footnotetext{
* Ciprian Turcan

Department of General and Applied Ethics, Faculty of Arts, Constantine the Philosopher University in Nitra, Slovakia E-mail: cturcan@ukf.sk
} 


\section{The rise of individualization and of the ideal of self-realization}

Most sociological theories interpret individualization as the structural consequence of transforming the social conditions of modern society. In this sense, Honneth also talks about individualization as a mutual overlap between the material and ideological processes that Western societies have undergone since the Second World War. They are the social processes that historian E. Hobsbawm even called "the social revolution" of the second half of the 20th century, with respect to their dramatic impact on the overall transformation of the society. The main processes of this transformation include the disappearance of the peasantry as the most widespread profession for the vast majority of the population, the intensive industrialization and urbanization along with the onset of the service sector, the rise of professions requiring high school and university education, gender emancipation and the growing role of women in society as a result of the mass entry of women into the labor market [5, pp. 287 - 320].

The common denominator of these far-reaching and dramatic changes that took place in an extremely short time in the course of one generation's life is the phenomenon of individualization. All these changes cleared the way for a substantial ascendant social mobility, linked to an increase in material living standards and an increase in leisure time, which ultimately altered not only the structure of social stratification but also, by its intensity, the category of this stratification itself. Social inequalities in society remained objectively maintained, but they have lost their subjective class dimension. So, at this point the individualization represents a complex process of "a social transformation within modernity, in the course of which people will be set free from the social forms of industrial society - class, stratification, family, gender status of men and women" [6, p. 87]. Increasing of the space for individual decision making and reducing of the social pressure to reproduce traditional, standardized social roles and lifestyles associated with social and gender status have led to an intensive diversification of life situations, to pluralization of lifestyles and of professed values, and to a reflexive grab of one's own life. This enabled the rise of a new form of reflexive individualism. Ch. Taylor talks about general widening of "expressive individualism" as about the desire of individuals to express their authentic individuality in their own way, which has its cultural roots in 18th century Romanticism [7, pp. 299 - 304], while N. Elias points out that the increasing social differentiation and individualization, regardless of the specific cultural development of society, lead to enforcement of the "ideal of unique and different", to the effort of individuals "to stand out from others, to stand on one's own feet and to seek fulfilment of a personal striving in one's own qualities, skills, possessions or achievements" [8, p. 141]. According to Honneth, it is primarily significant in this process that individuals are increasingly losing interest and willingness to understand their own lives as "a linear process of the development of an identity at the end of which would stand the demands of a profession and a division of labour by gender in the family", and instead of this the tendency has emerged "to think of the various possibilities for personal identity as being the stuff of experimental self-discovery" [4, p. 470]. Social emancipation meant a personal, subjective emancipation, and the socially formed and mediated morality has lost its normative power. Pluralism, diversity, originality, authenticity, otherness, freedom are the values of the new morality and the expressions of individual self-realization. Cultural and moral forms of life have been liberated from their social determination, and the conventions of social and personal behavior have been transformed towards even greater individual choice and freedom. Choice itself has become a fundamental value. Both, the normative respect for this choice and the continuation to increase the space for an individual choice was expected from the society. The sixties of the last century represent a kind of a symbol and breakthrough moment in this cultural transformation. Perhaps the most visible and most researched result of this transformation is the sexual revolution. However, ambitions and requirements were not limited only to the aspect of sexual and gender morality, but they had a wider social focus. "The revolts of young people in the '60s' were indeed, directed against a 'system' which smothered creativity, individuality and imagination. They rebelled against a 'mechanical' system in the name of more 'organic' ties; against the instrumental, and for lives devoted to things of intrinsic value; against privilege, and for equality; and against the repression of the body by reason, and for the fullness of sensuality" [7, p. 476].

\section{Institutionalization of the ideal}

In the $60 \mathrm{~s}$ and $70 \mathrm{~s}$, it really seemed that individualizing changes in the structure of the society would contribute to the strengthening of qualitative freedom the way that Honneth formulates in his thesis. At least from the normative perspective of critical theory, they created a promise of a more free society, because in its view, the expansion of space and of possibilities for self-realization of individuals are perceived as a reference criterion for evaluating the moral progress of society, which is carried out through social struggles for recognition. However, if we look at the next period through the optics of expectations and ideals of the sixties, we find out that their fulfillment did not occur or, it did only to a very limited extent. With regard to the idea of free and creative self-realization of the individual, this was greatly distorted and ideologically abused. According to Honneth's thesis, "the claim to self-realization was increasingly made into an institutional demand in the course of the last third of the twentieth century: at first hesitantly and subsequently on a massive scale, individuals were confronted with the expectation that they present themselves as being 'flexible' and willing to develop themselves if they wished to achieve success in their profession or in society" $[4$, p. 472$]$ and thus the ideal of self- 
realization "has developed into an ideology and productive force of an economic system that is being deregulated" [4, p. 474]. A number of factors contributed to this remarkable turn, to overturning of the ideal of self-realization. Honneth identifies the impact of the consumer and advertising industries, but he notes that much more important and decisive influence had the restructuring processes in the economic sphere, launched in the $80 \mathrm{~s}$, the new management concepts and new post-Taylorist strategies of business that led to the "normative subjectification of labor" when actors of work are beginning to be perceived not as dependent employees but as creative entrepreneurs.

The post-war welfare state, based on a set of fundamental social rights, developed extensive mechanisms of social and employment policy, the institutional forms of economic and labor market regulation that allowed relatively large emancipation of individuals from the market and contributed significantly to the individualization processes mentioned above. From the chronological point of view, it is mainly about the period of $50 \mathrm{~s}$ and 60 s that the sociologist Ulrich Beck denotes as "organized modernity," or Zygmunt Bauman as "solid modernity," in opposition to the terms "reflexive modernity" and "liquid modernity," which refer to the later development. The use of these adjectives is also justified by the fact that in the first period the social and political institutions fulfill their organizational and integrative functions, while later they are gradually re-evaluated and weakened. In the $70 \mathrm{~s}$ and $80 \mathrm{~s}$, in Western societies, the onset of neoliberal politics took place thanks to which the ideology of deregulation gradually prevailed as an effort to economize the social relations and to abolish existing institutional arrangements in favor of market conditions [9, pp. 39 - 63]. "The process of neoliberalization has, however, entailed much 'creative destruction', not only of prior institutional frameworks and powers (even challenging traditional forms of state sovereignty) but also of divisions of labour, social relations, welfare, provisions, technological mixes, ways of life and thought, reproductive activities, attachments to the land and habits of the heart" [9, p. 3]. In this ongoing process of dismantling of the welfare state, the expected ideal of self-realization ideologically justifies and legitimizes the radical changes in the normativeinstitutional structure of society.

Individualization represents a process of social, cultural, and gender emancipation of an individual, but does not and cannot mean his economical emancipation. The relation of material dependence of the individual from the society as such does not cease, only the specific form and mode of dependence are changed. If "individualization consists of transforming human 'identity' from a 'given' into a 'task'” [10, p. 31], then the means and the space for performing this task become, above all, the world of work. Socially emancipated individuals thus become directly dependent mainly on the labor market. Under the conditions of reflexive modernity, the Dahrendorf characteristics are even more valid: "modern societies are work societies, built around the work ethic and occupational roles," where "jobs are the entry tickets to the world of provisions. They determine people's incomes, including those from transfers, their social standing, their self-esteem and the way in which they organize their lives" [11, p. 143]. The labor market represents the key institution through which the ideal of self-realization is largely institutionalized. As a result of neo-liberal politics, the post-war model of the employers' society and forms of labor regulation weaken, and the general flexibility of the labor market, which strongly supports and radicalizes individualization, is on the rise.

The perspective of methods of social valuation of individuals will help us to understand this complex change. From the historical point of view, three basic patterns for the distribution of social valuation are known, i.e., origin, achievement, and solidarity, which were, in a different balancing ratio, jointly represented in individual types of society. If the transition from a traditional feudal society to a modern industrial society has been relatively successful in overcoming of the principle of origin as a source of social appreciation, then similar efforts are currently being made to overcome the principle of solidarity as one of the mechanisms for distributing of social appreciation. In the conditions of a deregulated economy, continued individualization is a process in which the social appreciation separates itself from a group status and is attributed to individuals directly on the basis of their individuality, their individual achievement. The way of distributing the social award is thus reduced only to the principle of achievement, which seems to correspond best to normative and structural conditions of the individualized society. According to Honneth, the individualistic achievement principle is a "part of an influential ideology insofar as it simply expressed the one-sided value horizon of those social groups which, because they possessed capital, had the means to reorganize economic reproduction" [12, p. 147].

\section{Conformal self-realization}

Instead of creating the expected space for the human subject to form its own value system, which the authentic ideal of selfrealization assumes, the formation and spread of a very narrow idea of self-realization arise, which is gaining increasingly strong institutional support. The values and morality of the economic elite of society become the normative source of the new ideal of self-realization. The institutionalized ideal of self-realization is created together with new growing labor market demands for qualification and personal engagement; it presumes willingness to identify with business goals of the company, to flexibly embrace innovative processes, to proactively take responsibility and to flexibly respond to changing market demands. Requirements are becoming more and more challenging and Bauman's comparison of the current world of work to top sport, which is overshadowed by uncertainty, is very compelling [13, pp. 24-25]. From a moral point of view, it assumes willingness of self-commodification and 
objectification, willingness to perceive itself as a labor force into which it is necessary to constantly invest for the purpose of its efficient reproduction, willingness to subordinate and sacrifice other aspects of human life [14]. The culture-reproduced ideal of self-realization thus represents a way of life that is essentially tied to market and consumption and is one of the expressions of penetration of economic imperatives into all areas of social action. The continuous differentiation of personal lifestyles takes place mainly in the background and within this ideal of selfrealization, rather than outside it or even in conflict with it, while for differentiation of lifestyles serves mainly consumption. With a certain reserve one could say that while performance serves as the principle of congruence, the consumption serves as the principle of differentiation where, in the context of consumer culture, the different products become the bearers of individual expression and serve even to define its own identity [15].

The value emphasis that is placed on flexibility, in the institutionalized ideal of self-realization, cannot be explained only by weakening of the relationship between capital and labor, thus as a consequence of flexibilisation and neoliberal deregulation of the labor market, but the dynamics of the development in modern society also significantly contributes to that fact because "the experience of modernization is an experience of acceleration $/ . . . /$ that acceleration is the central feature of the transformation of time structures, and as such a fundamental force that shapes the culture and social structure of modernity" [16, p. 21]. The ability to adapt to rapidly changing circumstances becomes a kind of objective condition not only for successful self-realization but also for the social realization of individual as such. Individualism ceases to be a subjective choice and, increasingly, becomes an objective necessity which occurs under external social pressure, "the tendency is towards the emergence of individualized forms and conditions of existence, which compel people - for the sake of their own material survival - to make themselves the center of their own planning and conduct of life" [6, p. 88].

If we have a look at the problem of the individualization of society and abusing of the ideal of self-realization from a wider historical and philosophical perspective, we find out that we are not dealing with a new phenomenon. As Karl Polanyi shows, a certain degree of individualization is present already at the very beginning of the market economy, "to separate labor from other activities of life and to subject it to the laws of the market was to annihilate all organic forms of existence and to replace them by a different type of organization, an atomistic and individualistic one" [17, p. 171] Moreover, Adorno and Horkheimer in the Dialectics of Enlightenment have already pointed out not only that the "principle of individuality was contradictory from the outset", because "in the individual's apparent freedom he was the product of society's economic and social apparatus", but also the phenomenon of overturning of ideals and fabrication of morality, when the subjects are "psychologically expropriated" [18, p. 125, 168]. What is qualitatively new in this case and what deserves our attention is the form and manner in which this expropriation is realized. It is no longer sufficient to accept and reproduce the presented and desired values and patterns of behavior passively and without resistance, but the subject itself must actively participate in its own expropriation.

\section{Conclusion}

A very widespread critique of individualization and individualism states that it poses a serious threat of social disintegration, that individualization threatens the very foundations of the functioning of society as such. An example of such criticism is also a well-known social theory of F. Fukuyama about "the great disruption" and "the reconstitution of social order," in which individualism figures as one of the main causes of social disruption and its overcoming as one of the conditions for the restoration of society [19]. Although it is undisputed that individualization decomposes the existing institutional forms of social cohesion and solidarity, it does not necessarily imply that it also decomposes the functioning of society itself. Moreover, from a normative point of view, also existing social institutions can be criticized to point to their power and ideological preconditions of functioning, and demanding their overcoming, not their restoration. In this situation, however, it is rather a hypothetical question because it appears that the functioning of the society seems to have been more or less successfully adapted to its individualized conditions. Individualization "is a structural characteristic of highly differentiated societies and does not endanger their integration but actually makes it possible" [20, p. xxi]. According to Beck, the social problems of reflexive modernity and forms of new poverty that bring changes to the labor market, the rise of social inequalities that has been happening since the 70s and 80 s of the 20th century [21, p. 237], the mass unemployment and under-employment, are not in conflict with individualization, but on the contrary, they explain it. The problems mentioned above no longer affect individuals in collective form, but as personal fate in specific phases of life, deprived of its socially visible contexts. The problem of individualization does not stem from its social dysfunction, but on the contrary from its functionality. The question is rather, what "price" must be paid by individuals for the functioning of such a society because following the institutionalized ideal of selfrealization people experience more likely frustration and suffering [22] associated with the desired claims and the expected results, rather than the fulfillment of their own desires.

\section{Acknowledgment}

This work was supported by the Slovak National Grant Agency under the projects No. VEGA 1/0888/16. 


\section{References}

[1] Also that is why in liberal discourse the key issue becomes the question of ethical neutrality of the state, as the question of the political coexistence of a pluralistic and individualized society. See KORENY, P.: From a Tolerant To an Ethically Neutral State. Human Affairs, 26(2), 186 - 200, 2016.

[2] TAYLOR, CH.: The Ethics of Authenticity. Harvard University Press, Cambridge, 1992.

[3] LASCH, CH.: The Culture of Narcissism. American Life in an Age of Diminishing Expectations. W.W. Norton, New York, 1991.

[4] HONNETH, A.: Organized Self-Realization. Some Paradoxes of Individualization. European Journal of Social Theory, 7(4), 463478, 2004.

[5] HOBSBAWM, E.: Age of Extremes. The Short Twentieth Century 1914 - 1991. Abacus, London, 1995.

[6] BECK, U.: Risk Society: Towards a New Modernity. SAGE Publications, London, 1992.

[7] TAYLOR, CH.: A Secular Age. Belknap Press of Harvard University Press, Cambridge, 2007.

[8] ELIAS, N.: The Society of Individuals. Continuum, New York, 2001.

[9] HARVEY, D.: A Brief History of Neoliberalism. Oxford University Press, Oxford, 2007.

[10] BAUMAN, Z.: Liquid Modernity. Polity Press, Cambridge, 2000.

[11] DAHRENDORF, R.: The Modern Social Conflict. An Essay on the Politics of Liberty. University of California Press, Berkeley, 1990.

[12] FRASER, N., HONNETH, A.: Redistribution or Recognition? A Political-Philosophical Exchange. Verso, London, 2003.

[13] BAUMAN, Z.: The Individualized Society. Polity Press, Cambridge, 2001.

[14] For example, according to Adler's psychological ethics, the life of an individual is oriented to three "Life Tasks," which "pertain to three major realms. The first area is life in a community and one's attitude towards neighbors, that is, one's social role, the second sphere is work and refers to one's occupation; and the third domain is love and partner relationship" - MARKOVA, D., CEHOVA, D.: Adlerian Ethics. ASIIP, London, 2016, p. 76. The reduction of life to just one of its dimensions, that occurs even when pursuing the ideal of self-realization, and the inability to fully fulfill other dimensions is the cause and source of pathological behavior and psychological, subjective suffering. At the same time, it is also one of the sources of alienation of the individual; for the question of alienation and searching for authenticity see KRALIK, R., TINLEY, S. J.: Kierkegaard's Ethics as an Answer to Human Alienation in Technocratic Society. Communications - Scientific Letters of the University of Zilina, 19(1), 25-29, 2017; and VALCO, M.: Kierkegaard's 'Sickness unto Death' as a Resource in our Search for Personal Authenticity. European Journal of Science and Theology, 12(1), 97-105, 2016; and VALCO, M., STURAK, P.: The "Relational Self": Philosophical-Religious Reflections in Anthropology and Personalism. Xlinguae, 11(1), 289-299, 2018.

[15] To the question of the impact of consumer culture and the media on identity formation, see LESKOVA, A., VALCO, M.: Identity of Adolescents and its Dimensions in Relation to Mass media: Philosophical-Ethical Reflections. Xlinguae, 10(3), 324-332, 2017.

[16] ROSA, H.: Social Acceleration: A New Theory of Modernity. Columbia University Press, New York, 2013.

[17] POLANYI, K.: The Great Transformation: The Political and Economic Origins of Our Time. Beacon Press, Boston, 2001.

[18] HORKHEIMER, M., ADORNO, T.W.: Dialectic of Enlightenment. Stanford University Press, Stanford, 2002.

[19] FUKUYAMA, F.: The Great Disruption: Human Nature and the Reconstitution of Social Order. Simon \& Schuster, New York, 2000.

[20] BECK, U., BECK-GERNSHEIM, E.: Individualization. Institutionalized Individualism and its Social and Political Consequences. SAGE Publications, London, 2002.

[21] PIKETTY, T.: Capital in the Twenty-First Century. Belknap Press, Cambridge, 2014.

[22] PETKOVSEK, R.: Violence and Ethics of the Cross in the Light of Existential Analytics and Mimetic Theory/Nasilje in etika kriza v luci eksistencialne analitike in mimeticne teorije (in Slovenian). Bogoslovni Vestnik, 74(4), 575-592, 2014. 